\title{
FUZZY MULTICRITERIA EVALUATION OF HEALTH RESEARCH INVESTMENTS
}

\author{
Cengiz KAHRAMAN ${ }^{\mathrm{a}}$, Aslı SÜDER ${ }^{\mathrm{b}}$, İhsan KAYA ${ }^{\mathrm{c}}$ \\ ${ }^{a}$ Department of Industrial Engineering, İstanbul Technical University, 34367 Macka, Istanbul, Turkey \\ ${ }^{\mathrm{b}}$ Department of Management Engineering, Istanbul Technical University, 34367 Macka, Istanbul, Turkey

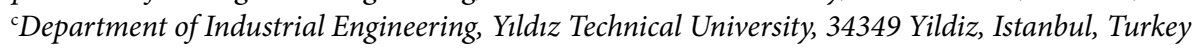

Received 07 January 2012; accepted 02 December 2012

\begin{abstract}
Health research and investments are expensive, and its explicit social, health and economic impacts are hard to define. There are many challenges and assumptions in defining specific returns on investment in health research. In the literature, there is no common approach to evaluate health research impacts. Single criterion methods are generally used with validated indicators to track overall outcomes or outcomes in a specific health research area. These methods have the ability of considering only one criterion at a time, which is usually the cost of the investment. A multicriteria method is proposed for taking care of many conflicting criteria of health research investments. The difficulty of measuring intangible criteria is captured by the fuzzy set theory. Fuzzy analytic hierarchy process (AHP) is used for the selection among four possible health research investment alternatives. A sensitivity analysis is made for the changes in the values of various parameters.
\end{abstract}

Keywords: health research, investment, fuzzy sets, AHP, multiple criteria.

Reference to this paper should be made as follows: Kahraman, C.; Süder, A.; Kaya, İ. 2014. Fuzzy multicriteria evaluation of health research investments, Technological and Economic Development of Economy 20(2): 210-226.

JEL Classification: I10, C3.

\section{Introduction}

The health area is considered to be one of the sectors with the highest research spending. Health research is fundamental to the development of improved health and healthcare. Despite its importance, and the role of policy in guiding the kind of research that gets addressed, there are very few empirical studies of health research policy (Shaw, Greenhalgh 2008).

Corresponding author İhsan Kaya

E-mail: ihkaya@yildiz.edu.tr; iekaya@yahoo.com 
Organizations can improve the quality of health care and patient satisfaction through investments in hard and soft technologies in order to cultivate and maintain a viable patient base (Ware et al. 1977). The methods used to undertake health and health care research are diverse. But all lead to the acquisition of new data, and share the need for storage, analysis and interpretation of those data. The massive rise in research outputs over recent years has led to a further division of health research into 'primary' and 'secondary' types. Primary research involves observation and experiment to gain new data. Secondary research involves finding and analyzing research done by others. Health and health care research are needed in order to reduce the uncertainty associated with the diagnosis, treatment and delivery of health care to all of those people in our society who are in need of it. There is a massive spectrum of such research, ranging from laboratory investigations on single molecules in tightly-controlled conditions, to observations on the complex behaviors within populations or systems of health care delivery (Dieppe 2005). The main elements of health research are illustrated in Figure 1.

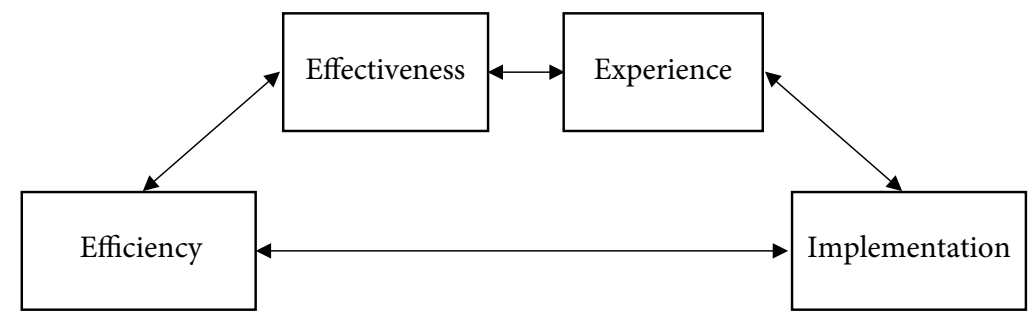

Fig. 1. The main elements of health research

Efficiency means value for money. As interventions become increasingly expensive, efficiency becomes increasingly important. Effectiveness denotes the ability of intervention to work for everyone who might need it. This raises the issue of whether the results of a trial are generalizable to the whole population. Experience shows that individuals prefer new option ' $x$ ' to old option ' $y$ ' to improve their health problems. Implementation means that we have to find ways of ensuring that the health care professionals, managers or policy makers take up the options that research findings find most appropriate.

The explicit and rational setting of priorities for investment in health research is accepted as an integral part of any research management process in health sector. Setting priorities in health research can serve to act as a catalyst for public debate, for bringing together different stakeholders, and for creating networks. These networks would ideally comprise of researchers in the public and private sectors, decision-makers in governments, and civil society (World Health Organization 2008).

Legitimacy and fairness are the fundamental principles that underlie effective priority setting processes. Legitimacy refers to the moral authority of decision makers. Fairness refers to the moral acceptability of the decision making process. At the core, priority setting involves adjudicating between a wide range of values, some of which conflict, including: benefit, evidence, cost, efficiency, equity, equality, benefit to a country's economy, severity of disease, prevalence of disease, solidarity, protection of the vulnerable, and more. Since the specific value drivers for health research prioritization may vary depending upon the 
context, these prioritization decisions must be made at the country level. A systematic and thorough mapping of the national context - political, environmental, economic, and health - as well as a mapping of financial and trained human resources will allow for a more realistic priority setting process and eventual implementation agenda. The context of the priority setting exercise should be defined upfront with as much specificity as possible. Examples of some of the critical contextual issues include: (a) whether the focus is on specific diseases, the health system, and/or the socio-economic determinants; (b) what is the target population, e.g. whether it is an entire country, a minority, children, or women; and (c) what is the time frame within which the research will be conducted and within which the priority setting process is predicted to have an impact. The priority setting exercise should include forward looking projections and forecasting in the context of the time frame of the exercise. For example, certain public health issues may not feature prominently in the present, but may have important implications for the future, and given the research timelines, they may require significant resource allocation in the near term (World Health Organization 2008).

Multiple attribute decision making (MADM)/multicriteria decision making (MCDM) is an important part of modern decision science. It has been extensively applied to various areas such as society, economics, management, military and engineering technology. For example, investment decision making, project evaluation, economic evaluation, personnel evaluation, etc. Since the object things are fuzzy, uncertainty and human thinking is ambiguous, the majority of multi-attribute decision making is uncertain and ambiguous, which is called fuzzy multiple attribute/criteria decision making (FMADM/FMCDM) (Liu, Zhang 2010; Liu 2011, 2009; Liu et al. 2011; Liu, Jin 2012a, b). The fuzzy set theory was used in many studies on investment problems and multicriteria evaluation of alternatives.

Baležentis et al. (2012) offered a novel procedure for integrated assessment and comparison of Lithuanian economic sectors on the basis of financial ratios and fuzzy MCDM methods. The complex of interrelated issues regarding integrated assessment of economic sectors was discussed. Keršulienè and Turskis (2011) integrated a fuzzy multi-criteria decision making (MCDM) algorithm using the principles of fusion of fuzzy information, additive ratio assessment (ARAS) method with fuzzy numbers (ARAS-F) and step-wise weight assessment ratio analysis (SWARA) technique. The proposed method was apt to manage information assessed using both linguistic and numerical scales in a decision making problem with a group of information sources. The aggregation process was based on the unification of information. Han and Liu (2011) aimed at solving hybrid multiple attributes decision-making problems under risk with attribute weight known and a new decision approach based on entropy weight and TOPSIS are proposed. First, the risk decision matrix was transformed into the certain decision matrix based on the expectation value. Then, the deviation entropy weight method was used to determine the attribute weights. Kaya and Kahraman (2011) proposed an e-banking website quality assessment methodology based on an integrated fuzzy AHP-ELECTRE approach. The weights of the criteria were generated by a fuzzy AHP analysis. Next, fuzzy ELECTRE was used to assess the quality levels of the websites. In the third step, a fuzzy dominance relation approach was used to rank the alternatives. In order to show the potentials of the proposed method, a case study in Turkish banking sector was reported together with a sensitivity analysis. 
Kahraman and Kaya (2010) applied two types of investment analyses. First, fuzzy parameters are used in the stochastic investment analysis. Then, another investment analysis was examined by using the concept of probability of a fuzzy event. Uçal and Kahraman (2009) suggested a new real options valuation model that will evaluate the investment in a more realistic way by postponing the defuzzification of parameters in early stages. The suggested model had been applied to the data of an oil field investment and in conclusion the loss of information caused by early-defuzzification has been determined. Liu (2009) proposed a method to resolve the multi-attribute decision-making problem utilizing fuzzy TOPSIS method.

The aim of this paper is to prioritize the possible investment alternatives in health research using a fuzzy multicriteria method, which has the ability of taking the conflicting criteria into account. The analytic hierarchy process (AHP) method will be utilized under fuzziness. Fuzziness provides a mathematical way to represent vagueness in humanistic systems. Fuzzy AHP lets us evaluate possible alternatives using pairwise comparisons with fuzzy numbers. Among many fuzzy AHP methods in the literature the Buckley's method, which is the least criticized one, has been preferred in our approach.

The rest of the paper is organized as follows. Section 1 presents a literature review on health research. Section 2 focuses on the evaluation criteria for health research investments. Section 3 presents the health research investment alternatives. Section 4 gives Buckley's (1985) fuzzy analytic hierarchy process. Section 5 includes an application and sensitivity analyses. Finally, the last section presents the conclusions.

\section{Literature review}

\subsection{Health research}

Researchers' attention to health research increases day by day. A literature on health may yield several published studies. In the following we give the works most related to our interest area.

Doblhoff-Dier and Collins (2001) state that research in the era of, e.g. epidemiology, immunology, development of new vaccines, diagnostic tools and therapeutics should be a top priority for every national and international research program. Human behavior (such as international travel), environmental changes, societal events, public health, microbial evolutions have profound influence on how and where outbreaks of infectious diseases can strike. Therefore research and development efforts will have to be extended to the nations of the developing world and to those infectious diseases that, only for the time being, seem to be confined to these regions. Green and Thorogood (2004) provide an introduction to qualitative methods that used examples of health research from a number of different settings, so that they can demonstrate how key methodological issues may have different implications in different contexts. Wunsch et al. (2005) provide an overview of health services research and specifically review the key components for evaluating and performing research in critical care using administrative data, including how to evaluate the quality of administrative data itself, and also how to evaluate the quality of studies that employ administrative data. Ozawa and Franco (2007) consider the public policy rationale for what the role of government should be in health innovation and investigates what the actual role of government has been across 
countries. They first examine the theoretical role for government in spurring innovation and scientific advancement in general. They then move to the specific case of health innovation, presenting the major reasons why governments actively intervene in this sector and how the health sector differs from other innovation sectors. Mukherjee and McGinnis (2007) present a methodology to identify key themes in research on e-healthcare. A qualitative meta-analysis approach is adopted. It allows for a thorough understanding of the existing literature pertaining to e-healthcare. Also, this analysis serves for further understanding of e-healthcare and its implications as a tool for improving the current management practices in the healthcare industry. Maclachlan et al. (2007) examine the prospects for integrating Internet platform GIS or 'web-GIS' into environmental justice and related public health research. Specifically, they document the development of a web-GIS created for investigating relationships between health, air quality and socioeconomic factors in Hamilton, Canada. After development of the web-GIS site, they assembled a focus group of public health professionals to test functionality and render opinions about the potential of the site and geographic information in their program implementation. Results show overwhelming support for the further integration of GIS into public health practice. The results also underscore the potential of web-GIS to alleviate concerns of cost and data availability that often limit the use of GIS in community debates centered on environmental justice issues. Bruce et al. (2008) design learning materials around a number of published research studies and information sources that address a variety of topics from the UK, Europe and developing countries.

\subsection{Fuzzy multicriteria methods and their applications in health research investments}

Nobre et al. (1999) present a multi-criteria decision making (MCDM) approach to support public health decision making that takes into consideration the fuzziness of the decision goals and the behavioral aspect of the decision maker. The approach is used to analyze the process of health technology procurement in a University Hospital in Rio de Janeiro, Brazil. The method, known as TODIM, relies on evaluating alternatives with a set of decision criteria assessed using an ordinal scale. Fuzziness in generating criteria scores and weights or conflicts caused by dealing with different viewpoints of a group of decision makers (DMs) are solved using fuzzy set aggregation rules. The results suggest that MCDM models, incorporating fuzzy set approaches, should form a set of tools for public health decision making analysis, particularly when there are polarized opinions and conflicting objectives from the DM group.

Vahidnia et al. (2009) consider the specific problem of creating a well-distributed network of hospitals that delivers its services to the target population with minimal time, pollution and cost. They develop a Multi-Criteria Decision Analysis process that combines Geographical Information System (GIS) analysis with the Fuzzy Analytical Hierarchy Process (FAHP), and use this process to determine the optimum site for a new hospital in the Tehran urban area. The GIS is used to calculate and classify governing criteria, while FAHP is used to evaluate the decision factors and their impacts on alternative sites. Three methods are used to estimate the total weights and priorities of the candidate sites: fuzzy extent analysis, center-of-area defuzzification, and the $\alpha$-cut method. The three methods yield identical priorities for the 
five alternatives considered. Fuzzy extent analysis provides less discriminating power, but is simpler to implement and compute than the other two methods. The usefulness of the new hospital site is evaluated by computing and accessibility index for each pixel in the GIS, defined as the ratio of population density to travel time.

Bardossy et al. (1991) give a brief review of three non-fuzzy-set techniques available for performing risk analysis under uncertainty (probabilistic error propagation, Bayesian analysis, and the Shannon entropy) using health-risk assessment to illustrate their approach. The advantages and difficulties in applying each of these techniques are pointed out. Mosmans et al. (2002) describe their proposed methodology while focusing on the construction of "health care channels" through causality analysis. The Belgian Ministry for Social Affairs decided to prolong that research by putting the accent on the development of a decision support system implementing the worked out methodology. This system is meant for the I.N.A.M.I.-R.I.Z.I.V.s (National Institute of Insurance against Disease and Handicap) actuaries to provide them with new analysis elements.

\section{Evaluation criteria for health research investments}

The main criteria for the evaluation of health research alternatives can be classified as follows:

- Infrastructure priorities;

- Effective use of resources;

- Addressing infrastructure needs efficiently;

- Establishing standards in implementation and management.

The explanations of these main criteria are given in the following (Australian Government, 2011).

\section{Infrastructure priorities in health sector}

Governments should invest in health to address health inequalities related to a wide range of health hazards (environmental, occupational, infrastructure such as roads, etc.). Investments into health infrastructure indicate that the government is prepared to manage new responsibilities in health sector to benefit the nation. Investments in health should be directed with respect to national infrastructure priorities. This criterion ensures that significant progress will be made in achieving the commonwealth's reform targets and it should be consistent with or should complement reform activities and assist the commonwealth in building a health system for the future; and should contribute to a balanced infrastructure investment across Turkey.

\section{Effective use of resources in health sector}

Improving people's healthy living conditions is only possible by effective use of limited resources. It is a must to decrease health problems. Projects should demonstrate that it will contribute to significant, sustainable and measurable ongoing improvement in health care. It should be supported by a good evidence-base that the project will lead to improvements in health outcomes. It should provide an indication of the relevant economic, social and environment costs, and relevant health, economic, social and environmental benefits of the proposal and demonstrate, comparing benefits and costs, that the proposal represents value for money. 


\section{Addressing infrastructure needs efficiently in health sector}

This covers extent of co-investment and collaboration, including that proposals generally will not impede investment in health infrastructure by other organizations, including the states and territories, universities, philanthropic and private organizations. Existing funding sources to maximize the impact of projects receiving health funding should be agreed before the commencement of funding. Proposals should have a project design consistent with current health sector standards and demonstrate that a range of options for achieving the results have been considered, and that the option put forward in the proposal is the most effective, strategic option.

\section{Establishing health sector standards in implementation and management}

Capacity of the organization to support, maintain and integrate new infrastructure into ongoing operations is an important issue. Proponents should identify how the facilities will be operated and maintained beyond the period of health funding, including the capacity to integrate facilities into their ongoing operations. They should demonstrate that they possess sufficient capacity and any other resources (such as funding for project maintenance or associated recurrent costs) to ensure the delivery of the project and realization of expected benefits. The organization has access to the human resources necessary to ensure the realization of expected benefits from the proposal.

\section{Health research investment alternatives}

Many possible health research investment alternatives exist in practice. Some of them are "Development of Treatments and Therapeutic Interventions", "Underpinning Research", "Aetiology", "Detection, Screening and Diagnosis", "Health and Social Care Services Research", "Management of Diseases and Conditions", and "Prevention of Disease and Conditions, and Promotion of Well-Being". The possible investment alternatives in health research for our study are determined as pharmaceuticals, cellular and gene therapies, medical devices, and surgery and radiotherapy, which are the sub research areas of Development of Treatments and Therapeutic Interventions (UKCRC 2009):

\section{A1-Pharmaceuticals}

These include identification and development of pharmaceutical small molecules, therapeutic vaccines, antibodies and hormones including:

- drug screening and development of delivery systems;

- mechanism of action including side effects and drug resistance;

- pharmacogenetics, prediction of genetic variation and responses to drugs.

\section{A2-Cellular and gene therapies}

Discovery and development of cellular, tissue and gene therapies including:

- gene therapy, stem cells therapy, and tissue engineering;

- development of delivery systems;

- development of culture systems. 


\section{A3-Medical devices}

Discovery and development of medical devices including:

- implantable devices, mobility aids, dressings, medical equipment and prostheses;

- biological safety assessments and investigation of adverse events;

- sterilization and decontamination of equipment or surfaces.

\section{A4-Surgery and Radiotherapy}

\section{i. Surgery.}

Development of surgical, obstetric and dental interventions including:

- histocompatability, transfusions, transplantations including xenograft studies;

- and bone marrow transplants;

- mechanisms of recovery, tolerance, rejection and side effects including infection.

ii. Radiotherapy.

Discovery and development of interventions including:

- radiobiology, radiotherapy, radioimmunotherapy, radiosensitisers, microwaves, ultrasound, laser and phototherapy;

- development of delivery systems;

- investigation of mechanisms of action and side effects.

\section{Buckley's method}

In the literature, there are many different fuzzy AHP algorithms. The first algorithm in fuzzy AHP was proposed by van Laarhoven and Pedrycz (1983), which compared fuzzy ratios described by triangular membership functions. Then, Buckley (1985) presented fuzzy priorities of comparison ratios whose membership functions trapezoidal. Chang (1996) proposed the use of triangular fuzzy numbers for pairwise comparison scale of fuzzy AHP, and the use of the extent analysis method for the synthetic extent values of the pairwise comparisons. In this chapter, Buckley's (1985) fuzzy AHP method is presented in detail. The steps of this method are given in the following (Hsieh et al. 2004):

Step 1. Pairwise comparison matrices are constructed. Each element $\left(\tilde{c}_{i j}\right)$ of the pairwise comparison matrix $(C)$ is a linguistic terms presenting which is the more important of two criteria. The pairwise comparison matrix is given by:

$$
\tilde{C}_{k}=\left|\begin{array}{cccc}
1 & \tilde{c}_{12} & \ldots & \tilde{c}_{1 n} \\
\tilde{c}_{21} & 1 & \ldots & \tilde{c}_{2 n} \\
\vdots & \vdots & \vdots: \vdots & \vdots \\
\tilde{c}_{n 1} & \tilde{c}_{n 2} & \ldots & 1
\end{array}\right|, k=1,2,3, \ldots, K,
$$

where $\tilde{C}_{k}$ is a pairwise comparison matrix belonging to $k^{\text {th }}$ expert for $F R_{m}$. For the evaluation procedure, the linguistic terms given in Table 1 are used. Geometric mean is used to aggregate expert opinions. 
Table 1. Linguistic scale for weight matrix (Hsieh et al. 2004)

\begin{tabular}{cll}
\hline Linguistic scales & Scale of fuzzy number & \\
\hline$(1,1,3)$ & Equally important & $(\mathrm{Eq})$ \\
$(1,3,5)$ & Weakly important & $(\mathrm{Wk})$ \\
$(3,5,7)$ & Essentially important & $(\mathrm{Es})$ \\
$(5,7,9)$ & Very strongly important & $(\mathrm{Vs})$ \\
$(7,9,9)$ & Absolutely important & $(\mathrm{Ab})$ \\
\hline
\end{tabular}

Step 2. Weights are calculated. At first, the fuzzy weight matrix is calculated by Buckley's Method as follows (Hsieh et al. 2004):

$$
\begin{gathered}
\tilde{r}_{i}=\left(\tilde{c}_{i 1} \otimes \tilde{c}_{i 2} \otimes \ldots \otimes \tilde{c}_{i n}\right)^{1 / n} ; \\
\tilde{w}_{i}=\tilde{r}_{i} \otimes\left(\tilde{r}_{1}+\tilde{r}_{2}+\ldots+\tilde{r}_{n}\right)^{-1},
\end{gathered}
$$

where $\tilde{r}_{i}$ is the geometric mean of fuzzy comparison value and $\tilde{w}_{i}$ indicated by triangular fuzzy numbers $\tilde{w}_{i}\left(L_{i}, M_{i}, U_{i}\right)$ is fuzzy weight of $i^{\text {th }}$ criterion.

Step 3. After the fuzzy relative weight matrix is obtained, defuzzification process which converts a fuzzy number into a crisp value is utilized. In this paper, total integral method is used for this aim. Liou and Wang (1992) proposed the total integral value method with an index of optimism $\omega \in[0,1]$. Let $\tilde{A}$ be a fuzzy number with left membership function $f_{\tilde{A}}^{L}$ and right membership function $f_{\tilde{A}}^{R}$. Then the total integral value is defined as (Kahraman et al. 2004):

$$
E_{\omega}(\tilde{A})=\omega E_{R}(\tilde{A})+(1-\omega) E_{L}(\tilde{A})
$$

where:

$$
E_{R}(\tilde{A})=\int_{\alpha}^{\beta} x f_{\tilde{A}}^{R}(x) d x
$$

and

$$
E_{L}(\tilde{A})=\int_{\gamma}^{\delta} x f_{\tilde{A}}^{L}(x) d x,
$$

where: $-\infty<\alpha \leq \beta \leq \gamma \leq \delta<\infty$. For a triangular fuzzy number, $\tilde{A}=(a, b, c)$, the total integral value is obtained by:

$$
E_{\omega}(\tilde{A})=\frac{1}{2}[\omega(a+b)+(1-\omega)(b+c)] .
$$

\section{Application and sensitivity analysis}

In this paper, possible investments in health research are analyzed and are evaluated by a fuzzy AHP methodology. For this aim, the criteria shown in Table 2 are used. There are four main criteria and eleven subcriteria. The number of the considered possible health research alternatives are four, namely: Pharmaceuticals; Cellular and gene therapies; Medical devices; and Surgery and radiotherapy.

The hierarchical structure of the problem is shown in Figure 2. 
Table 2. Evaluation criteria for investments in health research

\begin{tabular}{cl}
\hline \multicolumn{1}{c}{ Code } & \multicolumn{1}{c}{ Criteria } \\
\hline C1 & Infrastructure priorities \\
\hline C11 & Achieving common wealth's reform \\
C12 & Complementing reform activities \\
C13 & A balanced infrastructure investment \\
\hline C2 & Effective use of resources \\
\hline C21 & Improvement in health care \\
C22 & Improvements in health outcomes \\
\hline C3 & Infrastructure needs \\
\hline C31 & Co-investment and collaboration \\
C32 & Project quality and efficiency \\
\hline C4 & Established standards \\
\hline C41 & Human resources \\
C42 & Comprehensive risk management \\
C43 & Comprehensive implementation plan \\
C44 & Sufficient capacity \\
\hline
\end{tabular}

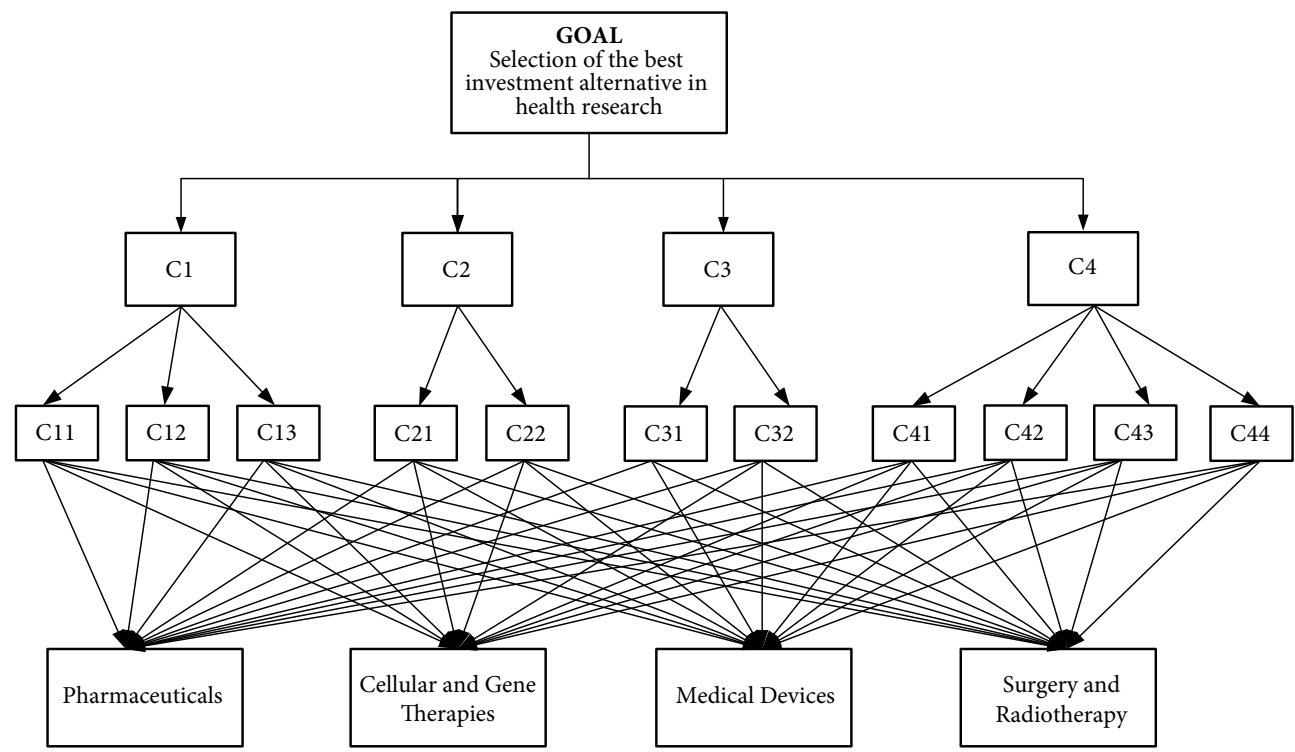

Fig. 2. The hierarchical structure for the best investment alternative in health research

Three decision makers among whom, one is a professor in Department of Industrial Engineering, one is an expert in Ministry of Health and the last one is an expert State Planning Organization, evaluate the decision process.

The linguistic evaluations of DMs which are shown in Table 3 are converted to fuzzy numbers as shown in Table 4 by using the linguistic scale explained in Table 1. 
Table 3. Decision maker's evaluations for criteria

\begin{tabular}{|c|c|c|c|c|c|c|c|c|c|c|c|c|}
\hline & \multicolumn{4}{|c|}{ D1 } & \multicolumn{4}{|c|}{ D2 } & \multicolumn{4}{|c|}{ D3 } \\
\hline & $\mathrm{C} 1$ & $\mathrm{C} 2$ & $\mathrm{C} 3$ & $\mathrm{C} 4$ & $\mathrm{C} 1$ & $\mathrm{C} 2$ & C3 & $\mathrm{C} 4$ & $\mathrm{C} 1$ & $\mathrm{C} 2$ & $\mathrm{C} 3$ & $\mathrm{C} 4$ \\
\hline $\mathrm{C} 1$ & & Vs & $\mathrm{Eq}$ & Es & & Es & Vs & Es & & Vs & $\mathrm{Eq}$ & Vs \\
\hline $\mathrm{C} 2$ & & & $1 /$ Es & $1 / \mathrm{Wk}$ & & & $1 / \mathrm{Wk}$ & $1 / \mathrm{Wk}$ & & & $1 /$ Es & $1 /$ Es \\
\hline C3 & & & & Wk & & & & Es & & & & Wk \\
\hline C4 & & & & & & & & & & & & \\
\hline
\end{tabular}

Table 4. Converted fuzzy numbers of DMs' evaluations for criteria

\begin{tabular}{|c|c|c|c|c|c|c|c|c|}
\hline & & & D1 & & & & D2 & \\
\hline & $\mathrm{C} 1$ & $\mathrm{C} 2$ & C3 & $\mathrm{C} 4$ & $\mathrm{C} 1$ & $\mathrm{C} 2$ & C3 & $\mathrm{C} 4$ \\
\hline $\mathrm{C} 1$ & & $(5,7,9)$ & $(1,1,3)$ & $(3,5,7)$ & & $(3,5,7)$ & $(3,5,7)$ & $(5,7,9)$ \\
\hline $\mathrm{C} 2$ & $(0.11,0.143,0.2)$ & & $(0.14,0.2,0.33)$ & $(0.2,0.33,1)$ & $(0.14,0.2,0.33)$ & & $(0.2,0.33,1)$ & $(0.2,0.33,1)$ \\
\hline C3 & $(0.33,1,1)$ & $(3,5,7)$ & & $(1,3,5)$ & $(0.14,0.2,0.33)$ & $(1,3,5)$ & & $(3,5,7)$ \\
\hline \multirow[t]{3}{*}{$\mathrm{C} 4$} & $(0.14,0.2,0.33)$ & $(1,3,5)$ & $(0.2,0.33,1)$ & & $(0.11,0.14,0.2)$ & $(1,3,5)$ & $(0.14,0.2,0.33)$ & \\
\hline & & & D3 & & & & & \\
\hline & $\mathrm{C} 1$ & $\mathrm{C} 2$ & C3 & $\mathrm{C} 4$ & & & & \\
\hline $\mathrm{C} 1$ & & $(3,5,7)$ & $(3,5,7)$ & $(5,7,9)$ & & & & \\
\hline $\mathrm{C} 2$ & $(0.14,0.2,0.33)$ & & $(0.2,0.333,1)$ & $(0.2,0.333,1)$ & & & & \\
\hline C3 & $(0.14,0.2,0.33)$ & $(1,3,5)$ & & $(3,5,7)$ & & & & \\
\hline $\mathrm{C} 4$ & $(0.11,0.14,0.2)$ & $(1,3,5)$ & $(0.14,0.2,0.33)$ & & & & & \\
\hline
\end{tabular}

The pairwise comparison matrix is obtained by using the geometric mean method suggested by Buckley (1985). For example $\tilde{c}_{13}$ is calculated as follows:

$$
\begin{aligned}
& \tilde{c}_{13}=((0.33,1,1) \otimes(0.143,0.200,0.333) \otimes(0.333,1,1))^{\frac{1}{3}} ; \\
& \tilde{c}_{13}=(0.251,0.585,0.693) .
\end{aligned}
$$

The other elements of comparison matrix can be obtained by the same computational procedure as shown in Table 5.

Then the fuzzy weights can be calculated. For example, $\tilde{r}_{1}$ is calculated as follows:

$$
\begin{aligned}
& \tilde{r}_{1}=((1,1,1) \otimes(4.217,6.257,8.277) \otimes(1.442,1.71,3.979) \otimes(4.217,6.257,8.277))^{\frac{1}{4}} ; \\
& \tilde{r}_{1}=(2.25,2.86,4.063) .
\end{aligned}
$$

The other values of $\tilde{r}_{i}$ are found as follows:

$$
\begin{aligned}
& \tilde{r}_{2}=(0.242,0.321,0.53) ; \\
& \tilde{r}_{3}=(0.932,1.721,2.22) ; \\
& \tilde{r}_{4}=(0.42,0.632,0.979) .
\end{aligned}
$$


Table 5. The pairwise comparison matrices of the four evaluation criteria

\begin{tabular}{lllll}
\hline & $\mathrm{C} 1$ & $\mathrm{C} 2$ & $\mathrm{C} 3$ & $\mathrm{C} 4$ \\
\hline $\mathrm{C} 1$ & $(1,1,1)$ & $(4.217,6.257,8.277)$ & $(1.442,1.71,3.979)$ & $(4.217,6.257,8.277)$ \\
\hline $\mathrm{C} 2$ & $(0.121,0.16,0.237)$ & $(1,1,1)$ & $(0.16,0.237,0.481)$ & $(0.179,0.281,0.693)$ \\
\hline C3 & $(0.251,0.585,0.693)$ & $(2.08,4.217,6.257)$ & $(1,1,1)$ & $(1.442,3.557,5.593)$ \\
\hline C4 & $(0.121,0.16,0.237)$ & $(1.442,3.557,5.593)$ & $(0.179,0.281,0.693)$ & $(1,1,1)$ \\
\hline
\end{tabular}

In the last step, the fuzzy weights $\left(\tilde{w}_{i}\right)$ can be calculated and defuzzified by using Liou and Wang's (1992) total integral method as shown in Table 6.

Table 6. Weights of criteria

\begin{tabular}{llc}
\hline & Fuzzy Value & $\begin{array}{l}\text { Defuzzified and } \\
\text { Normalized Value }\end{array}$ \\
\hline $\mathbf{W}_{1}$ & $(0.289,0.517,1.057)$ & 0.526 \\
\hline $\mathbf{W}_{2}$ & $(0.031,0.058,0.138)$ & 0.063 \\
\hline $\mathbf{W}_{3}$ & $(0.12,0.311,0.577)$ & 0.292 \\
\hline $\mathbf{W}_{4}$ & $(0.054,0.114,0.255)$ & 0.119 \\
\hline
\end{tabular}

According to Table 6, the criteria Infrastructure priorities (C1), is determined as the most important evaluation criterion.

The same procedures are also applied to determine the weights of sub-criteria. Then the weights for them are determined as shown in Table 7.

Table 7. The local and overall values of criteria and sub-criteria for health investment

\begin{tabular}{cclcc}
\hline & & \multicolumn{2}{c}{ Local } & Overall \\
\cline { 3 - 5 } & & Fuzzy Value & Crisp Value & Crisp Value \\
\hline C1 & & $(0.289,0.517,1.057)$ & & $\mathbf{0 . 5 2 6}$ \\
\hline & C11 & $(0.051,0.093,0.229)$ & 0.100 & 0.053 \\
\hline & C12 & $(0.129,0.265,0.644)$ & 0.280 & 0.147 \\
\hline & C13 & $(0.274,0.642,1.328)$ & 0.620 & 0.326 \\
\hline C2 & & $(0.031,0.058,0.138)$ & & $\mathbf{0 . 0 6 3}$ \\
\hline & C21 & $(0.573,0.848,1.227)$ & 0.843 & 0.053 \\
\hline & C22 & $(0.11,0.152,0.236)$ & 0.157 & 0.010 \\
\hline C3 & & $(0.12,0.311,0.577)$ & & 0.292 \\
\hline & C31 & $(0.197,0.288,0.644)$ & 0.325 & 0.095 \\
\hline & C32 & $(0.356,0.712,1.165)$ & 0.675 & 0.197 \\
\hline C4 & & $(0.054,0.114,0.255)$ & & 0.119 \\
\hline & C41 & $(0.109,0.244,0.539)$ & 0.250 & 0.030 \\
\hline & C42 & $(0.285,0.587,1.138)$ & 0.570 & 0.007 \\
\hline & C43 & $(0.03,0.055,0.132)$ & 0.060 & 0.014 \\
\hline & C44 & $(0.058,0.114,0.263)$ & 0.121 & \\
\hline
\end{tabular}


After the weights of criteria are determined, the alternatives are evaluated with respect to the evaluation criteria. For example, the linguistic evaluations of three decision makers for alternatives with respect to the sub-criterion Achieving common wealth's reform (C11), are shown in Table 8. These evaluations are converted to the fuzzy numbers as shown in Table 9.

All of the alternatives are evaluated with respect to $11 \mathrm{sub}$-criteria by DMs. The obtained results are summarized in Table 10. According to Table 10, the alternative Cellular and gene therapies (A2), is determined as the best alternative. The rank of the alternatives is as follows: \{A2-A3-A4-A1\}. This means Health research investment to Cellular and gene therapies has the largest priority with 0.498. Medical devices has the second priority with 0.270 . Surgery and Radiotherapy has the third priority and Pharmaceuticals does the forth.

Table 8. DMs' Evaluation for Alternative with respect to C11

\begin{tabular}{lllllllllllll}
\hline & \multicolumn{3}{c}{ D1 } & \multicolumn{1}{c}{ D2 } & \multicolumn{4}{c}{ D3 } \\
\cline { 2 - 12 } & A1 & A2 & A3 & A4 & A1 & A2 & A3 & A4 & A1 & A2 & A3 & A4 \\
\hline A1 & Vs & $1 /$ Wk & 1/Es & & Vs & 1/Es & $1 /$ Es & Vs & $1 / \mathrm{Wk}$ & $1 / \mathrm{Wk}$ \\
\hline A2 & & Wk & Es & & & Es & Es & & Es & Es \\
\hline A3 & & & Wk & & & Es & & & Es \\
\hline A4 & & & & & & & & & & & \\
\hline
\end{tabular}

Table 9. Converted fuzzy numbers of DMs' evaluations for alternatives

\begin{tabular}{|c|c|c|c|c|c|c|c|c|}
\hline & \multicolumn{4}{|c|}{ D1 } & \multicolumn{4}{|c|}{ D2 } \\
\hline & $\mathrm{A} 1$ & $\mathrm{~A} 2$ & $\mathrm{~A} 3$ & $\mathrm{~A} 4$ & $\mathrm{~A} 1$ & $\mathrm{~A} 2$ & $\mathrm{~A} 3$ & A4 \\
\hline $\mathrm{A} 1$ & & $(5,7,9)$ & $(0.2,0.33,1)$ & $(0.14,0.2,0.33)$ & & $(5,7,9)$ & $(0.14,0.2,0.33)$ & $(0.14,0.2,0.3)$ \\
\hline $\mathrm{A} 2$ & $(0.11,0.14,0.2)$ & & $(1,3,5)$ & $(3,5,7)$ & $(0.11,0.14,0.2)$ & & $(3,5,7)$ & $(3,5,7)$ \\
\hline A3 & $(1,3,5)$ & $(0.2,0.33,1)$ & & $(1,3,5)$ & $(3,5,7)$ & $(0.14,0.2,0.33)$ & & $(3,5,7)$ \\
\hline \multirow[t]{3}{*}{$\mathrm{A} 4$} & $(3,5,7)$ & $(0.14,0.2,0.33)$ & $(0.2,0.33,1)$ & & $(3,5,7)$ & $(0.14,0.2,0.33)$ & $(0.14,0.2,0.33)$ & \\
\hline & & D & 3 & & & & & \\
\hline & $\mathrm{A} 1$ & $\mathrm{~A} 2$ & $\mathrm{~A} 3$ & $\mathrm{~A} 4$ & & & & \\
\hline $\mathrm{A} 1$ & & $(5,7,9)$ & $(0.2,0.33,1)$ & $(0.2,0.33,1)$ & & & & \\
\hline A2 & $(0.11,0.14,0.2)$ & & $(3,5,7)$ & $(3,5,7)$ & & & & \\
\hline $\mathrm{A} 3$ & $(1,3,5)$ & $(0.14,0.2,0.33)$ & & $(3,5,7)$ & & & & \\
\hline A4 & $(1,3,5)$ & $(0.14,0.2,0.33)$ & $(0.14,0.2,0.33)$ & & & & & \\
\hline
\end{tabular}

Table 10. The evaluation results for health investment alternatives

\begin{tabular}{|c|c|c|c|c|c|c|c|c|c|c|c|c|c|}
\hline & \multicolumn{3}{|c|}{$\mathrm{C} 1$} & \multicolumn{2}{|c|}{$\mathrm{C} 2$} & \multicolumn{2}{|c|}{$\mathrm{C} 3$} & \multicolumn{4}{|c|}{$\mathrm{C} 4$} & & \\
\hline & \multicolumn{3}{|c|}{0.5264} & \multicolumn{2}{|c|}{0.0631} & \multicolumn{2}{|c|}{0.2917} & \multicolumn{4}{|c|}{0.1188} & & \\
\hline & $\mathrm{C} 11$ & $\mathrm{C} 12$ & $\mathrm{C} 13$ & $\mathrm{C} 21$ & $\mathrm{C} 22$ & C31 & C 32 & $\mathrm{C} 41$ & $\mathrm{C} 42$ & $\mathrm{C} 43$ & $\mathrm{C} 44$ & & \\
\hline & 0.100 & 0.280 & 0.620 & 0.843 & 0.157 & 0.325 & 0.675 & 0.250 & 0.570 & 0.060 & 0.121 & $\mathbf{W}$ & Rank \\
\hline A1 & 0.209 & 0.169 & 0.047 & 0.190 & 0.155 & 0.067 & 0.128 & 0.149 & 0.064 & 0.113 & 0.062 & 0.105 & 4 \\
\hline A2 & 0.301 & 0.532 & 0.572 & 0.664 & 0.641 & 0.598 & 0.501 & 0.075 & 0.121 & 0.038 & 0.652 & 0.498 & 1 \\
\hline A3 & 0.327 & 0.197 & 0.253 & 0.099 & 0.073 & 0.254 & 0.250 & 0.448 & 0.614 & 0.606 & 0.225 & 0.270 & 2 \\
\hline A4 & 0.163 & 0.101 & 0.128 & 0.047 & 0.131 & 0.081 & 0.122 & 0.328 & 0.200 & 0.244 & 0.062 & 0.127 & 3 \\
\hline
\end{tabular}


Table 11. The cases considered for sensitivity analysis

\begin{tabular}{lllll}
\hline & \multicolumn{4}{c}{ Weights of Criteria } \\
\cline { 2 - 5 } & C1 & C2 & C3 & C4 \\
\hline Case-I & 0.25 & 0.25 & 0.25 & 0.25 \\
\hline Case-II & 0.10 & 0.30 & 0.30 & 0.30 \\
\hline Case-III & 0.50 & 0.40 & 0.05 & 0.05 \\
\hline Case-IV & 0.05 & 0.05 & 0.40 & 0.50 \\
\hline Case-V & 0.10 & 0.10 & 0.10 & 0.70 \\
\hline Case-VI & 0.10 & 0.70 & 0.15 & 0.05 \\
\hline
\end{tabular}

The assumption in the calculations above was equal-weighted criteria. A sensitivity analysis is realized to see how the rank order of the alternatives behaves when the weights of the criteria are changed. In other words, we can see how sensitive our decision with respect to the changes in the criteria weights. The cases shown in Table 11 are taken into account. Notice that the first case, which means equal weights, is the one we have already studied above.

The six cases in Table 11 are analyzed and the results are summarized in Figure 3.

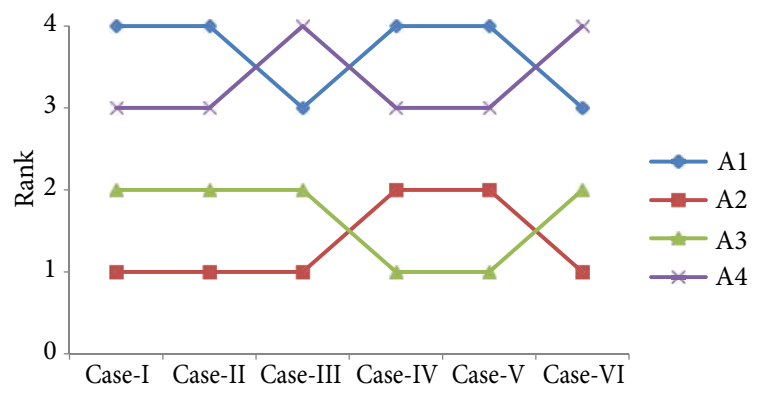

Fig. 3. The results of sensitivity analysis

According to Fig. 3, the ranking of the alternatives for Cases I and II is the same as the obtained results in the application. In Case-III, "Surgery and Radiotherapy (A4)" is determined as the worst alternative while "Medical Devices (A3)" becomes the third alternative. The best alternative is determined as "Medical devices (A3)" for Cases IV and V. The rank of the alternatives is determined as follows $\{\mathrm{A} 2-\mathrm{A} 3-\mathrm{A} 1-\mathrm{A} 4\}$ in Case-VI, which means "Cellular and gene therapies (A2)" is the best investment alternative. As the weight of the criterion "Effective use of resources (C2)" increases, the alternative "Cellular and gene therapies (A2)" moves to be the best alternative. As the weight of the criterion "Established standards (C4)" increases, the alternative "Medical devices (A3)" moves to be the best alternative.

\section{Conclusions}

Since reliable and relevant information of health research activities is needed for government and health sectors, usage of multi-criteria decision making is so critical in health research investments. 
Single criterion methods like econometric models or payback methods are usually utilized in decision making for health research investments. For both the econometric and payback methods of estimating return on investment in health research suffer from some common issues that need to be resolved in order for their results to be validated and for their results to be useful to each stakeholder audience. To be practical and useful, the best method for measuring return on health research investment must address many conflicting criteria.

Our paper has proposed a fuzzy multicriteria evaluation method for health research investment alternatives. Sensitivity analysis showed that criteria weights have an important role in the rank order of the alternatives. More alternatives and criteria can be incorporated to extend the problem content. The uncertainty in the evaluation judgments has been handled by the fuzzy set theory. This theory may be used together with another multicriteria method instead of AHP. TOPSIS, ELECTRE, or VIKOR are alternative methods, which may be integrated by the fuzzy set theory.

\section{References}

Australian Government, 2011. The Department of Health [online], [cited 12 December 2011]. Available from Internet: www.health.gov.au/internet/main/publishing.nsf/content/404ref.htm

Baležentis, A.; Baležentis, T.; Misiunas, A. 2012. An integrated assessment of Lithuanian economic sectors based on financial ratios and fuzzy MCDM methods, Technological and Economic Development of Economy 18(1): 34-53. http://dx.doi.org/10.3846/20294913.2012.656151

Bardossy, A.; Bogardi, I.; Duckstein, L. 1991. Fuzzy set and probabilistic techniques for health-risk analysis, Applied Mathematics and Computation 45(3): 241-268.

http://dx.doi.org/10.1016/0096-3003(91)90083-Y

Bruce, N.; Pope, D.; Stanistreet, D. 2008. Quantitative methods for health research: a practical interactive guide to epidemiology and statistics. John Wiley and Sons. 554 p. http://dx.doi.org/10.1002/9780470725337

Buckley, J. J. 1985. Fuzzy hierarchical analysis, Fuzzy Sets and Systems 17(3): 233-247. http://dx.doi.org/10.1016/0165-0114(85)90090-9

Chang, D. Y.1996. Applications of the extent analysis method on fuzzy AHP, European Journal of Operational Research 95(3): 649-655. http://dx.doi.org/10.1016/0377-2217(95)00300-2

Dieppe, P. 2005. Research on health and health care, in Handbook of Health Research Methods: Investigation, Measurement and Analysis. New York: McGraw-Hill, 3-11.

Doblhoff-Dier, O.; Collins, C. H. 2001. Biosafety: future priorities for research in health care, Journal of Biotechnology 85(2): 227-239. http://dx.doi.org/10.1016/S0168-1656(00)00362-X

Green, J.; Thorogood, N. 2004. Qualitative methods for health research. London: SAGE Publications.

Han, Z.; Liu, P. D. 2011. A fuzzy multi-attribute decision-making method under risk with unknown attribute weights, Technological and Economic Development of Economy 17(2): 246-258. http://dx.doi.org/10.3846/20294913.2011.580575

Hsieh, T. Y.; Lu, S. T.; Tzeng, G. H. 2004. Fuzzy MCDM approach for planning and design tenders selection in public office buildings, International Journal of Project Management 22(7): 573-584. http://dx.doi.org/10.1016/j.ijproman.2004.01.002

Kahraman, C.; Beskese, A.; Ruan, D. 2004. Measuring flexibility of computer integrated manufacturing systems using fuzzy cash flow analysis, Information Sciences 168(1-4): 77-94. http://dx.doi.org/10.1016/j.ins.2003.11.004

Kahraman, C.; Kaya, İ. 2010. Investment analyses using fuzzy probability concept, Technological and Economic Development of Economy 16(1): 43-57. http://dx.doi.org/10.3846/tede.2010.03 
Kaya, T.; Kahraman, C. 2011. A fuzzy approach to e-banking website quality assessment based on an integrated AHP-ELECTRE method, Technological and Economic Development of Economy 17(2):313-334. http://dx.doi.org/10.3846/20294913.2011.583727

Keršulienè, V.; Turskis, Z. 2011. Integrated fuzzy multiple criteria decision making model for architect selection, Technological and Economic Development of Economy 17(4): 645-666. http://dx.doi.org/10.3846/20294913.2011.635718

Laarhoven, P. J. M.; Pedrycz, W. 1983. A fuzzy extension of Saaty's priority theory, Fuzzy Set Systems 11: 229-241.

Liou, T. S.; Wang, M. J. 1992. Ranking fuzzy numbers with integral value, Fuzzy Sets and Systems 50(3): 247-255. http://dx.doi.org/10.1016/0165-0114(92)90223-Q

Liu, P. D. 2009. A novel method for hybrid multiple attribute decision making, Knowledge-Based Systems 22(5): 388-391. http://dx.doi.org/10.1016/j.knosys.2009.02.001

Liu, P. D.; Zhang, X. 2010. The study on multi-attribute decision-making with risk based on linguistic variable, International Journal of Computational Intelligence Systems 3(5): 601-609.

Liu, P. D. 2011. A weighted aggregation operators multi-attribute group decision-making method based on interval-valued trapezoidal fuzzy numbers, Expert Systems with Applications 38(1): 1053-1060. http://dx.doi.org/10.1016/j.eswa.2010.07.144

Liu, P. D.; Jin, F.; Zhang, X.; Su, Y.; Wang, M. 2011. Research on the multi-attribute decision-making under risk with interval probability based on prospect theory and the uncertain linguistic variables, Knowledge-Based Systems 24(4): 554-561. http://dx.doi.org/10.1016/j.knosys.2011.01.010

Liu, P. D.; Jin, F. 2012a. A multi-attribute group decision-making method based on weighted geometric aggregation operators of interval-valued trapezoidal fuzzy numbers, Applied Mathematical Modelling 36(6): 2498-2509. http://dx.doi.org/10.1016/j.apm.2011.09.006

Liu, P. D.; Jin, F. 2012b. Methods for aggregating intuitionistic uncertain linguistic variables and their application to group decision making, Information Sciences 205: 58-71.

http://dx.doi.org/10.1016/j.ins.2012.04.014

Maclachlan, J. C.; Jerrett, M.; Abernathy, T.; Sears, M.; Bunch, M. J. 2007. Mapping health on the internet: a new tool for environmental justice and public health research, Health \& Place 13(1): 72-86. http://dx.doi.org/10.1016/j.healthplace.2005.09.012

Mosmans, A.; Praet, J.-C.; Dumont, C. 2002. A decision support system for the budgeting of the Belgian health care system, European Journal of Operational Research 139(2):449-460. http://dx.doi.org/10.1016/S0377-2217(01)00369-1

Mukherjee, A.; McGinnis, J. 2007. E-healthcare: an analysis of key themes in research, International Journal of Pharmaceutical and Healthcare Marketing 1(4): 349-363.

http://dx.doi.org/10.1108/17506120710840170

Nobre, F. F.; Trotta, L. T. F.; Gomes, L. F. A. M. 1999. Multi-criteria decision making - an approach to setting priorities in health care, Statistics in Medicine 18(23): 3345-3354. http://dx.doi.org/10.1002/(SICI)1097-0258(19991215)18:23<3345::AID-SIM321>3.0.CO;2-7

Ozawa, J. K.; Franco, Q. C. 2007. The role of government in health research, Comprehensive Medicinal Chemistry II 1(24): 725-753. http://dx.doi.org/10.1016/B0-08-045044-X/00027-4

Shaw, S. E.; Greenhalgh, T. 2008. Best research - for what? Best health - for whom? A critical exploration of primary care research using discourse analysis, Social Science \& Medicine 66(12): 2506-2519. http://dx.doi.org/10.1016/j.socscimed.2008.02.014

Uçal, I.; Kahraman, C. 2009. Fuzzy real options valuation for oil investments, Technological and Economic Development of Economy 15(4): 646-669. http://dx.doi.org/10.3846/1392-8619.2009.15.646-669

UKCRC. 2009. UK clinical research collaboration [online], [cited 22 December 2011]. Available from Internet: www.ukcrc.org. 
Vahidnia, M. H.; Alesheikh, A. A.; Alimohammadi, A. 2009. Hospital site selection using fuzzy AHP and its derivatives, Journal of Environmental Management 90(10): 3048-3056. http://dx.doi.org/10.1016/j.jenvman.2009.04.010

Ware, J. E.; Davies-Very, A.; Stewart, A. L. 1977. The measurement and meaning of patient satisfaction: a review of the literature, RAND Publication (P-6021), Santa Monica, CA.

World Health Organization. 2008. Priority setting methodologies in health research. Geneva, Switzerland.

Wunsch, H.; Harrison, D. A.; Rowan, K. 2005. Health services research in critical care using administrative data, Journal of Critical Care 20(3): 264-269. http://dx.doi.org/10.1016/j.jcrc.2005.08.002

Cengiz KAHRAMAN. He is a Professor in Industrial Engineering Department at Istanbul Technical University. He published about 150 journal papers and about 120 conference papers. He is the Guest Editor of many international journals and the Editor of many international books from Springer and Atlantis Press. His research areas are engineering economics, quality control and management, statistical decision making, multicriteria decision making, and fuzzy decision making.

Aslı SÜDER. She received her PhD degree from Istanbul University on International Business. She is currently an Associate Professor, Dr at İstanbul Technical University Department of Business Engineering. Main research interests include crisis management, automotive industry, globalization and organizational culture.

İhsan KAYA. He received BS and MSc degrees in Industrial Engineering from Selçuk University. He also received $\mathrm{PhD}$ degree from Istanbul Technical University on Industrial Engineering. He is currently an Associate Professor, Dr at Ylldız Technical University Department of Industrial Engineering. He has published over 100 papers. His main research interests include process capability analysis, quality management and control, statistical and multicriteria decision making, and fuzzy sets applications. 